\title{
Extracorporeal Shockwave Lithotripsy with Tamsulosin in Clearance of Upper Ureteral Calculi- A Randomized Control Clinical Trial
}

\author{
Md Safiul Alam Babul ${ }^{1}$, Md Waliul Islam², Shariful Islam Khan ${ }^{3}$, Mohammad Habibur Rahman ${ }^{4}$, Anup \\ Roy Chowdhury ${ }^{5}$, Abul Hasanat Mohammad Afzalul Haque ${ }^{6}$, AHM Mostofa Kamal ${ }^{7}$, Abdul Matin \\ Anamur Rashid Choudhury ${ }^{8}$
}

Received: 23 - 06 - 2020

Accepted: 07 - 09 - 2020

Conflicts of interest: None

Keywords: ESWL, Tamsulosin, Upper ureteric stone

\begin{abstract}
Background of the study: Urolithiasis has an incidence in the world of about $5 \%$ and the probability of a recurrence within 5-7 years is 50\% (Parmar, 2004). Exact data about its prevalence is not known in Bangladesh but it is quite common as seen in outpatient department. It is more common in northern part of the country, male suffer more than female (M:F: 3:1) (Salam, 2002). Symptomatic ureteral calculi represent the most common condition encountered by an urologist in an emergency setting (Pak, 1998). Intervention is recommended for individuals with larger stones, especially greater than $5 \mathrm{~mm}$ (Kupeli et al., 1998). The treatment of this pathology was revolutionized with the introduction, in the late 1980s, of extracorporeal shock wave lithotripsy (ESWL), a non-invasive technology that has become one of the primary treatments for urinary stones. Its success rates vary depending on stone size and location and by the type of lithotripter employed. Medical expulsion therapy (MET) can play a key role in support of ESWL: specifically, expulsion is done by diuretics, calcium antagonists, anti-edema agents, and alpha-blockers. A few studies have reported their effectiveness (Borghi et al., 1994, Cervenakov et al., 2002, Porpiglia et al., 2002,Dellabella et al., 2003).
\end{abstract}

Objective: This study is carried out to find out the role of Tamsulos in stone clearance in patientswith upper ureteral stone after extracorporeal shock wave lithotripsy (ESWL).

Methods \& Material: This randomized control clinical trialwas performed in Department of Urology, National Institute of Kidney Diseases and Urology, Sher-EBangla Nagar, Dhaka during the period from July 2015 to June 2017. A total of 70 cases with upper ureteric stone were included during the study period. Patients were selected randomly in every alternate sequence, odd numbers for experimental group, Tamsulosin+

ESWL, group A \& even numbers for control group, only ESWL, group B. Stone clearance rate, number of ESWL session and stone expulsion time were evaluated.

1. Assistant Professor \& Resident Surgeon (Urology), National Institute of Kidney diseases and Urology (NIKDU), Sher-E-Bangla Nagar, Dhaka-1207, Bangladesh.

2. Associate Professor of Urology, Shaheed Suhrawardy Medical College \& Hospital (ShSMCH), Sher-E-Bangla Nagar, Dhaka-1207, Bangladesh

3. Medical Officer (Urology), National Institute of Kidney diseases and Urology (NIKDU), Sher-E-Bangla Nagar, Dhaka-1207, Bangladesh .

4. Assistant Registrar (Urology), National Institute of Kidney diseases and Urology (NIKDU), Sher-E-Bangla Nagar, Dhaka-1207, Bangladesh .

5. Assistant Registrar Transplant Surgery, National Institute of Kidney diseases and Urology (NIKDU), Sher-E-Bangla Nagar, Dhaka1207, Bangladesh.

6. Assistant Professor cum Resident Surgeon (Urology), Dhaka Medical College \& Hospital (DMCH), Dhaka-1000, Bangladesh.

7. Assistant Registrar Transplant Surgery, National Institute of Kidney diseases and Urology (NIKDU), Sher-E-Bangla Nagar, Dhaka1207, Bangladesh.

8. Associate Professor of Urology, National Institute of Kidney diseases and Urology (NIKDU), Sher-E-Bangla Nagar, Dhaka-1207, Bangladesh . Correspondence: Dr. Md Safiul Alam Babul, Assistant Professor \& Resident Surgeon (Urology), National Institute of Kidney diseases and Urology (NIKDU), Sher-E-Bangla Nagar, Dhaka-1207, Bangladesh, Email: drmdsafiulalambabul@gmail.com 
Results: In this study showed complete stone clearance one month after ESWL in Group A was 16(89\%) and Group B was 16(84.21\%) for stone size 6 to $10 \mathrm{~mm}$. Comparison of clearance rate between two groups in stone size 6 to $10 \mathrm{~mm}$ was not statistically significant (p value >.05). Complete stone clearance one month after ESWL in Group A was 13(76\%) and Group B was 07(43.75\%) for stone size 11 to $15 \mathrm{~mm}$. Comparison of clearance rate between two groups in stone size 11 to $15 \mathrm{~mm}$ was statistically significant ( $p$ value $<.05)$. In this study requirement of number of ESWL sessions according to the stone size showed, in case of 6 to $10 \mathrm{~mm}$ stone size, average ESWL sessions 1.28 0.5 in Group A and 1.53 \pm 0.7 in Group $B$ and in case of 11 to $15 \mathrm{~mm}$ stone size, average ESWL sessions $1.29 \pm 0.5$ in Group $A$ and $1.62 \pm 0.7$ in Group B. Comparison of ESWL sessions between two groups were statistically significant ( $p$ value $<.05$ ). In this study mean expulsion time of stone in Group A was 22.34 \pm 12.23 days and in Group B was $32.34 \pm 21.96$ days. Comparison of stone expulsion time between two groups were statistically significant ( $p$ value <.05).

Conclusion: Tamsulosin results in increased stone-free rates and in lower percentages of patients requiring re-treatment. Tamsulosin can be self-administered and can play a key role in the choice between tamsulosin after ESWL and only ESWL for upper ureteric stone disease treatment. Use of tamsulosin makes the expulsive medical therapy suitable for improving overall outcomes of ESWL treatment for upper ureteral stones. Tamsulosin helps in clearance of upper ureteral stones after ESWL.

\section{Introduction}

Urinary stone have plagued humans since the earliest record of civilization. Urinary calculi are the third most common affliction of the urinary tract, exceeded only by urinary tract infections and pathologic conditions of the prostate (Stoller, 2008). Urolithiasis has an incidence in the world of about $5 \%$ and the probability of a recurrence within 5-7 years is 50\% (Parmar, 2004). Exact data about its prevalence is not known in Bangladesh but it is quite common as seen in outpatient department. It is more common in northern part of the country, male suffer more than female (M:F: 3:1) (Salam, 2002). Symptomatic ureteral calculi represent the most common condition encountered by an urologist in an emergency setting (Pak, 1998). In the presence of normal renal function and absence of infection, observation is generally preferred for ureteral calculi with a maximum of $5 \mathrm{~mm}$ diameter (Lingeman et al., 2009). Intervention is recommended for individuals with larger stones, especially greater than $5 \mathrm{~mm}$ (Kupeli et al., 1998). The treatment of this pathology was revolutionized with the introduction, in the late 1980s, of extracorporeal shock wave lithotripsy (ESWL), a non-invasive technology that has become one of the primary treatments for urinary stones. Its success rates vary depending on stone size and location and by the type of lithotripter employed.
Now-a-day, ESWL has many advantages: a low morbidity rate, high patient compliance, ability to treat on an outpatient basis, and no requirement for anesthesia - except in children, in whom it still remains a first-line treatment (Muslumanoglu et al., 2003).

Extracorporeal shock wave lithotripsy has been recommended as a first-line treatment modality for upper ureteral calculi in several studies with a success rate of $80 \%$ to $90 \%$ (Mitre et al., 1992, Mogensen and Andersen, 1994, Gnanapragasam et al., 1999). Recently, medical expulsion therapy (MET) has shown encouraging results in facilitating spontaneous clearance of lower ureteral calculi as well as fragments after ESWL for renal and/ or ureteral calculi (Kupeli et al., 2004, Gravina et al., 2005, Hollingsworth et al., 2006, Bhagat et al., 2007, Naja et al., 2008). Tamsulosin, an á1A adrenoceptor blocker, has been used in several recent MET experiments, but the results of studies are variable and most of them are being carried out on patients with lower ureteral calculi (Autorino et al., 2005, Losek and Mauro, 2008, Resim et al., 2005). However, study on upper ureteral calculi is scarce. Tamsulosin administration for patients with upper ureteral stones would improve the stone-free rate as the stone size increases is still under debate. So, aim of this study is to evaluate the effects of tamsulosin on stone clearance of upper ureteral calculus, treated by ESWL. 


\section{Materials and Methods}

This randomized control clinical trial was performed in the Department of Urology, National Institute of Kidney Diseases and Urology, Sher-E- Bangla Nagar, Dhaka during the period from July 2015 to June 2017 after taking the ethical clearance from the Ethical Committee of the same institute. A total of 70 cases with upper ureteric stone were included during the study period. Patients were selected randomly in every alternate sequence, odd numbers for experimental group, Tamsulosin+ ESWL, group A \& even numbers for control group, only ESWL, group B). Stone clearance rate, number of ESWL session and stone expulsion time were evaluated.

All patients were evaluated by detailed history and clinical examinations of each patient were done and recorded in predesigned data entry form. All preoperative routine investigations- total blood count, blood urea, serum creatinine, random blood sugar, coagulation profile (BT, CT, PT \& APTT), routine urine examination and culture sensitivity. Ultra sonogram of KUB region with MCC with PVR, Plain X-ray KUB region (Antero- posterior), Intravenous urography (IVU) were done in all patients to see the condition of kidney, location of stone grade of hydronephrosis and to measure the size of stone in $100 \%$ film of plain XRay KUB, Electrocardiography (ECG) were also done. Pre ESWL urine samples were sterile in all patients.

Patients in group A received Tamsulosin $0.4 \mathrm{mg}$ once a day, just before the session of ESWL and continued for 3 months or until the clearance of calculi, which was earlier. Patients in group B did not receive Tamsulosin or any other medication to facilitate expulsion of stone after ESWL. ESWL monotherapy with Storz Lithostar ( $3^{\text {rd }}$ generation) lithotripter was used to treat all patients with upper ureteric stones $>5 \mathrm{~mm}$ to up to 15 $\mathrm{mm}$ in size. Patients were advised to take a mild laxative in previous night before the procedure and tab ultracarbon was given for 2 days to reduce intestinal gas and for clear stone visualization. All the patients were in nothing per oral from morning and were given intravenous fluid with diclofenac sodium suppository 30 minutes before ESWL. In a single session, maximum of 3000 shock waves were given. All patients were advised to take $2500 \mathrm{cc}$ fluid daily, and analgesic diclofenac was on demand during the study period. If stone at the level of transverse process we use Inj. Fentanyl intravenously. After the procedure they were discharged from lithotripsy unit on the same day. Prophylactic antibiotics were given to all patients one hour before the ESWL.

At each follow-up, Plain X-Ray KUB, ultrasonography of KUB, urine analysis as well as measurement of serum creatinine was performed. Successful results were defined as complete stone clearance or presence of less than a 3-mm clinically insignificant and asymptomatic residual calculus. Those who did not complete the follow-up without clearance were excluded from the study. Unsuccessful patients underwent ureteroscopy (URS) as an auxiliary procedure. The primary outcome of this study was the success rate, and the secondary outcomes were stone clearance time, ESWL sessions required for stone clearance.

All collected questionnaire was checked very carefully to identify the error in the data. Data processing work were consisting of registration schedules, editing computerization, preparation of dummy table, analyzing and matching of data.

\section{Results}

Total 70 cases were selected randomly from the patients attending urology outpatient department of NIKDU with upper ureteric stone. Among them 35 patients were placed in Group A experimental group \& 35 patients were placed in Group B control group. Distribution of respondents in terms of different parameters is shown in tabulated form and statistical analysis was done in both groups to see statistical significance. $\mathrm{p}$ value less than 0.05 was considered significant.

\section{Age distribution between groups:}

Age distribution of Group-A was 18-72 years and Group-B was from 19-71years. The mean \pm SD age of group-A and Group-B were 43.14 \pm 13.21 and $43.71 \pm 12.96$ years, respectively. There was no significant difference of mean age between the two groups ( $p$ value $>0.05$ )

\section{Sex distribution of the patients:}

Sex distribution of the study population shows in Group A - 28(80\%) were male and $07(20 \%)$ were in female with male female ratio 4:1. In Group B $24(68.6 \%)$ were male and $11(31.4 \%)$ were in female with male female ratio 2.18:1. There was no significant difference of sex distribution between the two groups ( $\mathrm{p}$ value $>0.05$ ). 


\section{A. Stone clearance after 01 month of ESWL}

Complete stone clearance one month after ESWL in Group A was 16 (89\%) and Group B was 16(84.21\%) for stone size 6 to $10 \mathrm{~mm}$. Comparison of clearance rate between two groups in stone size 6 to $10 \mathrm{~mm}$ was not statistically significant ( $\mathrm{p}$ value $>.05$ ). Complete stone clearance one month after ESWL in Group A was 13(76\%) and Group B was 07 (43.75\%) for stone size 11 to $15 \mathrm{~mm}$. Comparison of clearance rate between two groups in stone size 11 to $15 \mathrm{~mm}$ was statistically significant ( $p$ value $<.05$ ). Overall complete stone clearance one month after ESWL in Group A was $29(82.86 \%)$ and Group B was 23(71.43\%). Comparison of clearance rate between two groups in stone size 06 to $15 \mathrm{~mm}$ was statistically significant ( $\mathrm{p}$ value $<.05$ )

\section{B. Stone clearance after 02 month of ESWL}

Stone clearance after two month after ESWL in rest of the patient in Group A was 01(50\%) and Group B was $01(33.33 \%)$ patients for stone size 6 to $10 \mathrm{~mm}$. Comparison of clearance rate between two groups in stone size 6 to $10 \mathrm{~mm}$ was not statistically significant ( $p$ value $>.05$ ). Stone clearance two month after ESWL in Group A was 01(25\%) and Group B was 04(44.44\%). Comparison of clearance rate between two groups in stone size 11 to $15 \mathrm{~mm}$ was statistically not significant ( $p$ value $>.05$ ). Overall stone clearance after two month after ESWL in rest of the patient in Group A was 02(33.33\%) and Group B was 05(41.67\%) for stone size 6 to $15 \mathrm{~mm}$. Comparison of clearance rate between two groups in stone size 6 to $15 \mathrm{~mm}$ was not statistically significant ( $\mathrm{p}$ value $>.05$ ).

Table-I : Stone clearance after 01 month of ESWL

\begin{tabular}{|c|c|c|c|c|c|c|}
\hline \multirow[t]{2}{*}{ Stone size $(\mathrm{mm})$} & & \multicolumn{2}{|c|}{ Group $\mathrm{A}(\mathrm{N}=35)$} & \multicolumn{2}{|c|}{ Group $\mathrm{B}(\mathrm{N}=35)$} & \multirow[t]{2}{*}{$\mathrm{p}$ value } \\
\hline & & No & $\%$ & $\mathrm{No}$ & $\%$ & \\
\hline \multirow[t]{2}{*}{6 to 10} & Cleared & 16 & 88.9 & 16 & 84.21 & \multirow[t]{2}{*}{.677} \\
\hline & Not cleared & 02 & 11.1 & 03 & 15.79 & \\
\hline \multirow[t]{2}{*}{11 to15 } & Cleared & 13 & 76.5 & 07 & 43.75 & \multirow[t]{2}{*}{.032} \\
\hline & Not cleared & 04 & 23.5 & 09 & 56.25 & \\
\hline Overall 6 to 15 & Cleared & 29 & 82.86 & 23 & 65.71 & .035 \\
\hline
\end{tabular}

Group A: patients with ESWL+Tamsulosin

Group B: patients with Only ESWL

Chi-square test was done to analyze the data

Table-II : Stone clearance after 02 month of ESWL

\begin{tabular}{|c|c|c|c|c|c|c|}
\hline \multirow[t]{2}{*}{ Stone size $(\mathrm{mm})$} & & \multicolumn{2}{|c|}{ Group A $(\mathrm{N}=06)$} & \multicolumn{2}{|c|}{ Group B $(\mathrm{N}=12)$} & \multirow[t]{2}{*}{$p$ value } \\
\hline & & No & $\%$ & No & $\%$ & \\
\hline \multirow[t]{2}{*}{6 to 10} & Cleared & 01 & 50.00 & 01 & 33.33 & .580 \\
\hline & Not cleared & 01 & 50.00 & 02 & 66.67 & \\
\hline \multirow[t]{2}{*}{11 to15 } & Cleared & 01 & 25.00 & 04 & 44.44 & .438 \\
\hline & Not cleared & 03 & 75.00 & 05 & 55.56 & \\
\hline Overall 6 to 15 & Cleared & 02 & 33.33 & 05 & 41.67 & .436 \\
\hline
\end{tabular}

Group A: patients with ESWL+Tamsulosin

Group B: patients with Only ESWL

Pearson Chi-square test was done to analyze the data 


\section{C: Stone clearance after 03 month of ESWL}

Stone clearance three month after ESWL in rest of the patient in both Group were 0 for stone size 6 to $10 \mathrm{~mm}$. Comparison of clearance rate between two groups in stone size 6 to $10 \mathrm{~mm}$ was statistically not significant ( $p$ value $>.05$ ). Stone clearance two month after ESWL in rest of the patient in Group A was 01 (33.33\%) and Group B was $02(40 \%)$ for stone size 11 to $15 \mathrm{~mm}$. Comparison of clearance rate between two groups in stone size 11 to $15 \mathrm{~mm}$ was not statistically significant ( $p$ value $>.05$ ). Overall stone clearance three month after ESWL in rest of the patient in Group A was 01(25\%) and Group B were 02(28.57\%) patients. Comparison of clearance rate between two groups in stone size 11 to $15 \mathrm{~mm}$ was statistically not significant ( $\mathrm{p}$ value $>.05$ )

\section{Stone Clearance Time}

Mean clearance expulsion time of stone in Group A was $22.34 \pm 12.23$ days and in Group B was 32.34 \pm 21.96 days. Comparison of stone clearance time between two groups were statistically significant $(p$ value $<.05$ )

\section{ESWL sessions}

On comparison to requirement of number of ESWL sessions according to the stone size showed, in case of 6 to $10 \mathrm{~mm}$ stone size, average ESWL sessions $1.28 \pm 0.5$ in Group A and 1.53 \pm 0.7 in Group B and in case of 11to $15 \mathrm{~mm}$ stone size, average ESWL sessions $1.29 \pm 0.5$ in Group A and 1.62 \pm 0.7in Group B. Comparison of number of ESWL sessions between two groups were statistically significant ( $p$ value $<.05$ )

Table-III : Stone clearance after 03 month of ESWL

\begin{tabular}{|c|c|c|c|c|c|c|}
\hline \multirow[t]{2}{*}{ Stone size $(\mathrm{mm})$} & & \multicolumn{2}{|c|}{ Group A $(\mathrm{N}=04)$} & \multicolumn{2}{|c|}{ Group B(N=07) } & \multirow[t]{2}{*}{$p$ value } \\
\hline & & No. & $\%$ & No. & $\%$ & \\
\hline \multirow[t]{2}{*}{6 to 10} & Cleared & 0 & 0 & 0 & 0 & .580 \\
\hline & Not cleared & 01 & 100 & 02 & 100 & \\
\hline \multirow[t]{2}{*}{11 to15 } & Cleared & 01 & 33.33 & 02 & 40 & .576 \\
\hline & Not cleared & 02 & 66.67 & 03 & 60 & \\
\hline Overall6 to 15 & Cleared & 01 & 25 & 02 & 28.57 & .484 \\
\hline
\end{tabular}

Group A: patients with ESWL+Tamsulosin

Group B: patients with Only ESWL

Pearson Chi-square testwas done to analyze the data

Table-IV: Stone Clearance Time

\begin{tabular}{|c|c|c|c|}
\hline Mean clearance time & Group $\mathrm{A}(\mathrm{N}=35)$ & Group $B(N=35)$ & $p$ value \\
\hline & No & No & \\
\hline Mean $\pm S D(d)$ & $22.34 \pm 12.23$ & $32.34 \pm 21.96$ & 0.008 \\
\hline
\end{tabular}

Group A: patients with ESWL+Tamsulosin

Group B: patients with Only ESWL

Fisher's Exact test was used to analyze the data d = days

Table-V : ESWL sessions

\begin{tabular}{lccc}
\hline Stone size $(\mathrm{mm})$ & Group $\mathrm{A}(\mathrm{N}=35)$ & Group B(N=35) & p value \\
\hline 6 to 10 & $1.28 \pm 0.5$ & $1.53 \pm 0.7$ & .021 \\
11 to15 & $1.29 \pm 0.5$ & $1.62 \pm 0.7$ & .027 \\
\hline
\end{tabular}

Group A: patients with ESWL+Tamsulosin

Group B: patients with Only ESWL

Fisher's Exact test was used to analyze the data 


\section{Discussion}

The present study was designed to evaluate and compare the effects of Tamsulosin administration after ESWL in patients with upper ureteric calculi of different sizes. Seventy patients were included in this study and attend at follow up clinic. Thus 70 patients were analyzed, 35 patients placed in Group A (Tamsulosin + ESWL) and 35 patients placed in Group B (only ESWL) for upper ureteric stone management.

In this study age distribution of Group-A was 18-71 years and Group-B was from $18-72$ years. The mean \pm SD age of group-A and Group-B were 43.14 \pm 13.21 and $43.71 \pm 12.96$ years, respectively. There was no significant difference of mean age between the two groups ( $\mathrm{p}$ value $>0.05$ ). In different international study like Kobayashi et al. (2008), Agarwal et al. (2009) and Singh et al. (2011) showed mean age of 56.76 \pm 8.69 , $32.4 \pm 8.7$ and $32.20 \pm 12.22$ years, respectively.

In this study sex distribution showed in Group A$28(80 \%)$ were male and $07(20 \%)$ were in female with male female ratio 4:1. In Group B- 24(68.6\%) were male and11 $(31.4 \%)$ were in female with male female ratio 2.18:1. There was no significant difference of sex distribution between the two groups ( $p$ value $>0.05$ ). Singh et al. (2011) showed Male: Female ratio was 44:15 which was comparable to this study.

In this study showed in Group A - 18 (51.43\%) cases stone size was 6 to $10 \mathrm{~mm}, 17(48.57 \%)$ cases stone size was 11 to $15 \mathrm{~mm}$ and mean stone size was $10.69 \pm 2.78$ $\mathrm{mm}$. In Group B - 19 (54.29\%) cases stone size was 6 to $10 \mathrm{~mm}, 16(45.71 \%)$ cases stone size was 11 to $15 \mathrm{~mm}$ mean stone size $10.70 \pm 2.96 \mathrm{~mm}$. There was no significant difference between the two groups ( $p$ value $>0.05$ ) in respect to stone size. The above distribution correlates with the study done by Kobayashi et al. (2008) and Agarwal et al. (2009) showed mean \pm SD (mm) $10.61 \pm 4.45$ and $9.4 \pm 1.9 \mathrm{~mm}$, respectively. In another study conducted by Singh et al. (2011) showed 6 to $10 \mathrm{~mm}$ stone size in 30 patients and 11 to $15 \mathrm{~mm}$ stone size in 29 patients which was comparable to this study. In this study showed complete stone clearance one month after ESWL in Group A was 16(89\%) and Group B was 16(84.21\%) for stone size 6 to $10 \mathrm{~mm}$. Comparison of clearance rate between two groups in stone size 6 to $10 \mathrm{~mm}$ was not statistically significant ( $\mathrm{p}$ value $>.05$ ). Complete stone clearance one month after ESWL in Group A was 13 (76\%) and Group B was $07(43.75 \%)$ for stone size 11 to $15 \mathrm{~mm}$. Comparison of clearance rate between two groups in stone size 11 to
$15 \mathrm{~mm}$ was statistically significant (p value <.05) which were more less similar to the study conducted by Kobayashi et al. (2008) where stone-free rate was $84.21 \%$ (32/38 patients) after 4 weeks with $0.2 \mathrm{mg}$ Tamsulosin after ESWL and 88.24\% (30/34) in control group. Similarly another study conducted by Singh et al. (2011) showed stone clearance 90\% (27/30) patients for stone size 6 to $10 \mathrm{~mm}$ and $79.3 \%(23 / 29)$ patients for stone size 11 to $15 \mathrm{~mm}$. In our study overall complete stone clearance one month after ESWL in Group A was 29/35 (82.86\%) and Group B was 23/35 (71.43\%). Comparison of overall clearance rate between two groups in stone size 06 to $15 \mathrm{~mm}$ was statistically significant ( $p$ value <.05) which was similar to the study conducted by Singh et al. (2011) where stone clearance rate was 50/59 (85\%) with Tamsulosin group and $41 / 58$ (70.69\%) in control group.

In this study showed overall stone clearance two months after ESWL in rest of the patient in Group A was $02(33.33 \%)$ and Group B was 05(41.67\%) for stone size 6 to $15 \mathrm{~mm}$. Comparison of clearance rate between two groups in stone size 6 to $15 \mathrm{~mm}$ was not statistically significant ( $p$ value $>0.05$ ). Overall stone clearance three month after ESWL in rest of the patient in Group A was 01 (25\%) and Group B were 02 (28.57\%) patients. Comparison of clearance rate between two groups in stone size 11 to $15 \mathrm{~mm}$ was statistically not significant ( $\mathrm{p}$ value $>0.05$ )

In this study showed complete stone clearance three month after ESWL in Group A was 17 (94.45\%) and Group B was 17 (89.47\%) patients for stone size 6 to 10 $\mathrm{mm}$. Comparison of clearance rate between two groups in stone size 6 to $10 \mathrm{~mm}$ was not statistically significant ( $\mathrm{p}$ value $>.05$ ). Complete stone clearance two month after ESWL in Group A was 15(88.24\%) and Group B was $13(81.25 \%)$ for stone size 11 to $15 \mathrm{~mm}$. Comparison of clearance rate between two groups in stone size 11 to $15 \mathrm{~mm}$ was not statistically significant ( $\mathrm{p}$ value $>.05$ ) which were more less similar to the study conducted by Agarwal et al. (2009) where stone-free rate was 95\% (532/38 patients) after 4 weeks with $0.2 \mathrm{mg}$ Tamsulosin after ESWL and $90 \%$ in control group at 3 month follow up. Similarly another study conducted by Singh et al. (2011) showed stone clearance 93\% (28/30) patients for stone size 6 to $10 \mathrm{~mm}$ and $90 \%$ (26/29) patients for stone size 11 to $15 \mathrm{~mm}$. In our study overall complete stone clearance three month after ESWL in Group A was $32(91.43 \%)$ and Group B was $30(85.71 \%)$ patients. Comparison of clearance rate between two groups in stone size 11 to $15 \mathrm{~mm}$ was statistically not significant 
( $\mathrm{p}$ value $>.05$ ) which was similar to the study conducted by Singh et al. (2011) where stone clearance rate was 54/59 (81.3\%) with Tamsulosin group and 50/ $58(86.21 \%)$ in control group.

In this study mean expulsion time of stone in Group A was 22.34 \pm 12.23 days and in Group B was 32.34 \pm 21.96 days. Comparison of stone expulsion time between two groups were statistically significant ( $p$ value $<.05$ ). In different international study like Kobayashi et al. (2008), Agarwal et al. (2009) and Singh et al. (2011) showed mean expulsion time was $15.66 \pm 6.14$, $30.7 \pm 19.6$ and $26.78 \pm 11.96$ days, respectively in Tamsulosin group and in control group $27.74 \pm 25.36$ days, $39.0 \pm 19.9$ and $31.28 \pm 18.31$ days, respectively.

In this study requirement of number of ESWL sessions according to the stone size showed, in case of 6 to 10 $\mathrm{mm}$ stone size, average ESWL sessions $1.28 \pm 0.5$ in Group A and 1.53 \pm 0.7 in Group B and in case of 11to $15 \mathrm{~mm}$ stone size, average ESWL sessions $1.29 \pm 0.5$ in Group A and 1.62 \pm 0.7 in Group B. Comparison of ESWL sessions between two groups were statistically significant ( $\mathrm{p}$ value $<.05$ ). In international study like Agarwal et al. (2009) showed mean ESWL sessions was $1.6 \pm 0.8$ in Tamsulosin group and in control group was $2.0 \pm 0.9$. In that study ESWL sessions was more may be due to different ESWL machine. In another study Singh et al. (2011) showed the frequency of SWL sessions was also compared between Tamsulosin and control groups and a statistically significant difference was found $(\mathrm{p}=.034)$.

\section{Conclusion}

Tamsulosin results in increased stone-free rates and in lower percentages of patients requiring re-treatment. Tamsulosin can be self-administered and can play a key role in the choice between Tamsulosin after ESWL and only ESWL for upper ureteric stone disease treatment. Use of Tamsulosin makes the expulsive medical therapy suitable for improving overall outcomes of ESWL treatment for upper ureteral stones. Tamsulosin helps in clearance of upper ureteral stones after ESWL.

\section{References}

1. Agarwal, M. M., Naja, V., Singh, S. K., Mavuduru, R., Mete, U. K., Kumar, S. \& Mandal, A. K. 2009. Is there an adjunctive role of tamsulosin to extracorporeal shockwave lithotripsy for upper ureteric stones: results of an open label randomized nonplacebo controlled study. Urology, 74, 989-92.

2. Bhagat, S. K., Chacko, N. K., Kekre, N. S., Gopalakrishnan, G., Antonisamy, B. \&Devasia, A.
2007. Is there a role for tamsulosin in shock wave lithotripsy for renal and ureteral calculi? J Urol, $177,2185-8$.

3. Cervenakov, I., Fillo, J., Mardiak, J., Kopecny, M., Smirala, J. \&Lepies, P. 2002. Speedy elimination of ureterolithiasis in lower part of ureters with the alpha 1-blocker-Tamsulosin. IntUrolNephrol, 34, 25-9.

4. Dellabella, M., Milanese, G. \&Muzzonigro, G. 2003. Efficacy of tamsulosin in the medical management of juxtavesical ureteral stones. J Urol, 170, 2202-5.

5. Gravina, G. L., Costa, A. M., Ronchi, P., Atiotogal, G. P., Angelucci, A., Castellani, D., Narcisi, F. \&Nivicenti, C. 2005. Tamsulosin treatment increases clinical success rate of single extracorporeal shock wave lithotripsy of renal stones. Urology, 66, 24-8.

6. Itoh, Y., Kojima, Y., Yasui, T., Tozawa, K., Sasaki, S. \&Kohri, K. 2007. Examination of alpha 1 adrenoceptor subtypes in the human ureter. Int J Urol, 14, 749-53.

7. Kupeli, B., Irkilata, L., Gurocak, S., Tunc, L., Kirac, M., Karaoglan, U. \&Bozkirli, I. 2004. Does tamsulosin enhance lower ureteral stone clearance with or without shock wave lithotripsy? Urology, 64, 1111-5.

8. Losek, R. L. \& Mauro, L. S. 2008. Efficacy of tamsulosin with extracorporeal shock wave lithotripsy for passage of renal and ureteral calculi. Ann Pharmacother, 42, 692-7.

9. Margaret, S. P. \&Lotan, Y. 2007. Etiology, Epidemiology and Pathogenesis. In: Wein, A. J., Kavoussi, L. R., Novick, A. C., Partin, A. W. \& Peters, C. A. (eds.) Campbell-Walsh Urology. 9 ed. Philadelphia: Saunders Elsevier.

10. Muslumanoglu, A. Y., Tefekli, A., Sarilar, O., Binbay, M., Altunrende, F. \&Ozkuvanci, U. 2003. Extracorporeal shock wave lithotripsy as first line treatment alternative for urinary tract stones in children: a large scale retrospective analysis. J Urol, 170, 2405-8.

11. Resim, S., Ekerbicer, H. \&Ciftci, A. 2005. Effect of tamsulosin on the number and intensity of ureteral colic in patients with lower ureteral calculus. Int J Urol, 12, 615-20.

12. Singh, A., Alter, H. J. \&Littlepage, A. 2007. A systematic review of medical therapy to facilitate passage of ureteral calculi. Ann Emerg Med, 50, $552-63$. 